of origin of the white corpuscles in these glands and elsewhere is unknown. A recent investigation by Dr. Klein, of Vienna, appears to furnish some clue to the discovery of this point, for he has demonstrated that a process of division of white corpuscles may, under favourable conditions, be observed to occur, a statement which, if corroborated by further researches, will prove of much importance both in physiology and pathology. In the blood of the water-newt, he remarks, three kinds of colourless cells may be distinguished, though their differences are not very strongly marked. In one of these forms the clump of protoplasm, of which the corpuscle is formed, assumes an hour-glass form, and with the performance of the liveliest movements in each half, ultimately divides into two, in each of which a nuclenr structure is visible. In a second kind the protoplasm forms a flat transparent disc, from the border of which a projection containing a distinct nucleus forms and gradually becomes detached. In a third form a kind of pinching off occurs of a minute portion from the general mass. The primary corpuscles may divide twice or thrice.

Les Mondes for March 3 Ist contains a translation of Prof. Tyndall's article in NATURE for the $1 ;$ th of the same month, on Floating Matters and Beams of Light.

MessRs. W. \& A. K. Johnston are preparing a series of Botanical Diagrams for Schools and Colleges, uniform with their "IHustrations of Natural Philosophy," 50 in. by 42 in. A good series of diagrams is very much wanted by botanical lecturers; the parts should be on a larger scale than in the late Prof. Henslow's diagrams published under the authority of the Government School of Science and Art, and the series more complete than that issued by the Christian Knowledge Society, which is very good as far as it goes, and remarkably cheap.

Tre Marlborough College Natural Mistory Society has published its report for the half-year ending Christmas 1869 , from which we gather, that beyond all question a real taste for science is taking firm root at Marlborough, though here and there, in the various papers, we get all too glowing descriptions, instead of the sober evidence of the keen eye of the observer. Here, for instance, is a description of the cuttle fish:- "And while I enumerate the greatest oddities to be seen in the 'motley crew' of fishes, shall I forget thee, $O$ cuttle, that lookest so innocent and harmless, till some white-waistcoated visitor takes thee up condescendingly, when with one mighty effort thou contractest thy muscles, and in an instant sendest a mighty stream of thy own peculiar ink over that erst virgin waistcoat? Ol, the inimitable look of pity and contempt then depicted on the faces of the natives! If by thy squirts and fliks, $O$ cuttle, thou hast made an enem,y, thou hast made one that will never molest thy inky tribe again. It is interesting to know that these murky creatures are provided witl backbones which have the peculiar quality of ink-erasing."

THERE is in the West Riding a Geological and Polytechnic Society, which publishes an annual report of proceedings. In that for 1869 an account is given of the meeting held at Wakefield, together with a number of papers on the history, antiquities, and mineral products of the county. The author of "On the Rocks of the neighbourhood of Pontefract," shows that there is coal erough along the line of the Lancashire and Yorkshire Railway, to yield nearly ten million tons a year for 489 years : and that the prospect of getting further supplies below the Mag. nesian Limestone and the New Red Sandstone is very pro. mising. The Rev. Scott F. Surtees contributes an argumentative paper to prove that the memorable battle between Harold of England and Harold of Norway was fought, not at Stamford Brig, but at Pontefract, and that the memory thereof is preserved by the name Ponte-fract-broken bridge. Other papers contain notices of the extinct fauna of Yorkshire, of flint implements, and of certain singular ancient pits in the neighbourhood of Ripon.

A PARAGRAPH appears in a recent number of the San Francisco Bulletin, stating that deer, antelope, bear, and elk constitute the large game of California. Deer are found in great abundance, and many hundreds are killed yearly on Tamalipas. The deep gulches, woods, and covers of Marin County afford excellent sport to the deer hunter. Elk do not range nearer than the Oregon line, but a few are still met with on the banks of the Sacramento and San Joaquin rivers, where in former years they were so abundant. The brown and black bear are also hunted in Marin County, and along various parts of the coast range. White and grey geese are found in all the bay counties, on the lakes, and up the rivers in abundance. Duck are shot in the same localities, of which the most valued is the mallard, which remains and breeds in the country. Then come the redhead, springtail pigeon, wood duck, blue and green winged teal, broadbill, spoonbill, sawbill, whistler, butterball, fantail, or Dutchman, and Cadwell's. Quail abound in the surrounding counties. In the immediate neighbourhood of the city quail are scarce, being trapped and slaughtered for the markets so earnestly, that here they are now almost exterminated. Rabbits are also found in the quail grounds. The English or jack snipe are shot in the freshwater marshes on the San Joaquin and Sacra. mento rivers, in the Amador, Gilroy, and Santa Clara valleys. Of the bay snipe there is an abundant variety, such as curlew, willet, whitewings, plover, yellowlegs, robin, doewitch, ringmeck, and sandpiper. The grouse, one of the finest game birds, frequents Mendocino and the upper counties of the State; several attempts have been made to stock the lower counties with these birds, but with little success. Trout abound in all the rivers running into the bay, and are taken with both bait and fly, but principally the former.

\section{REMARKABLE SPECTRA OF COMPOUNDS OF ZIRCONIA AND URANTUM}

THOUGH the spectra of different salts of bases which show well-marked absorption bands often differ in detail, yet they generally resemble one another so much that there is no difficulty in recognising each element. Judging from facts hitherto known, it was more probable that spectra of the new type described in my former paper* were due to a new element than that they were merely due to a combination of zirconium with uranium, and that there seemed to be no reason for suspecting a few special compounds of uranium would give spectra with bands unlike all others. Uranic salts, when in a state of moderately fine powder, give a spectrum not only showing absorption-bands, but also those which depend on fluorescence, and are characteristic of light reflected from the powder. + These two kinds of bands can be easily distinguished by means of a plate of deep blue cobalt glass, which proves that the abnormal bands seen in the spectra of the compounds of zirconia with the oxides of uranium are due to genuine absorption and not to fluorescence.

In studying the spectra of crystalline blow-pipe beads, it seemed desirable to examine those made with carbonate of soda, with or without a little borax. Though beads of carbonate of soda crystal. lise on cooling, so as to be only partially translucent, yet with strong direct sunlight well-marked spectra may be seev. For example, in the oxidising flame uranic oxide is easily dissolved by carbonate of soda alone, and when quickly cooled an orangecoloured bead is obtained, probably containing uranate of soda in a vitreous condition. It gives a single well-marked absorption. band in the green, with so small a quantity of the oxide, that in a bead $\frac{1}{8}$ inch in diameter $\frac{1}{200}$ grain shows the spectrum to the best advantage, and even $\frac{1}{10000}$ grain can be easily detected. In examining the various products from jargons in order to study the supposed new earth in a state of purity, a small quantity of a dark-coloured substance was obtained, apparently zirconia, containing some oxide which communicated a green tint to a glassy, borax blowpipe-bead, but yet not sufficiently

* Proceedings of R. S. vol. xvii. p. $5 \times x$.

+ See Stokes's paper, Phil. Trans. 1852, p. 463 and 1853, p. 392. 
distinct to show that it was due to uranous oxide. Though the presence of zirconia prevented solution by pure carbonate of soda, the addition of a little borax enabled me to prove that uranic oxide is really present in some jargons. Such then being the case, it seemed desirable to ascertain whether the oxides of uranium would give rise to any special spectra when present along with zirconia in crystalline blowpipe-beads. To my astonishment I found that the spectra were precisely the same as those obtained in the case of what I had though to be an approximately pure new earth. * Hence the very abnormal spectra, which seemed sufficient to establish the existence of a new earth, are really due to compounds of zirconia with the oxides of uranium, which have such a power ful action on light, that an almost inappreciable amount is sufficient to produce the spectra to great perfection-in fact so small an amount, that the total quantity which misled me was only a few thousandths of a grain ; and its presence might easily have remained unsuspected, if I had not discovered the carbonate of soda test just named. In the case of transparent blowpipe-beads of borax with microcosmic salt, it is requisite to have as much as about $\frac{x}{60}$ grain of uranous oxide to show faintly the characteristic absorption-bands, whereas, when present along with zirconia in the crystalline beads, $50 \frac{1}{0} 00$ grain gives an equally well-marked spectrum; and $\frac{1}{200}$ grain shows it far better than a larger quantity, which makes the beads too opaque. These very minute quantities were obtained by the repeated division of a small known weight, either before or after fusion with borax. This spectrum also differs very considerably from the spectra of the usual salts or blowpipe-beads of uranous oxide. On comparing them side by side, the only common peculiarity is the fact of there being numerous absorption-bands distributed over a large part of the spectrum; but they do not correspond in either number or position. On the contrary, they differ almost as much as possible; and the clarker bands in the spectrum of this zirconia compound occur where the transmitted light is the brightest in other cases. One of the most striking peculiarities of the spectrum of some jargons is, that when light passes in a direction perpendicular to the principal axis of the crystal, and the spectrum is divided by means of a double-image prism into two spectra, having the light polarised in opposite planes, though some of the absorption-bands are of equal intensity in both images, yet others are compara. tively absent, some in one and some in the other: whereas, in the case of other dichroic crystals, all the absorption-bands are usually more distinct in one image, and fainter, or even comparatively absent, in the other. The general character of the spectrum was entirely unlike that of all the known compounds of uranic oxide. Instead of the moderately broad absorption-bands in the blue end, ignited jargons give a most unusually large number of narrow black lines, extending from the red end, so that nearly all occur in that part of the spectrum which is entirely free from bands in all previously known compounds of uranic oxide. Besides uranium, and several of the more common earths and oxides, I have detected in some zircons erbium, didymium, yttria, and another substance which exists in such small quantity that I have not yet been able to ascertain whether or no it is the suspected new earth. These accidental constituents do not indeed occur in sufficient quantity to be of importance, except as modifying the physical and optical properties, the didymium giving the usual characteristic absorption-bands (zircons from Sveneroe, Norway), and the manganese, the same spectrum as that of garnets (zircons from an unknown locality in Siberiat). The oxide of uranium is so easily reduced at a high temperature to the state of protoxide in a borax-bead, with excess of boric acid, and is so readily peroxidised at a dull-red heat, when crystallised along with borate of zirconia, that there seemed good reason to refer the change in the spectra to temperature rather than to the state of oxidisation, until after it was found that they were due to uranium. By gently flaming the crystalline bead, the spectrum is entirely altered, and presents five well-marked absorption-bands, all of which occur at the red end, where no trace of bands exists in the case of ordinary uranic salts. I have not found any other element besides zirconia which causes uranium to give similar abnormal spectra, at all events in similar conditions. A few have special characters, but the majority exert little or no influence. Even when the blowpipe-beads are crystalline, they show only the usual spectra of the oxides of uranium. Moreover no such great change in the character of the spectra of other

* Figs. $\mathbf{r}$ and 2 of my former paper.

+ For both of these $I$ am indebted to my kind friend $M r$. David Forbes. elements which give absorption-bands is to be seen when they are combined with zirconia. So far as my present experience goes, it seems as if such very abnormal spectra were met with only in the case of these remarkable compounds of zirconia with the oxides of uranium. These facts now put us in a position to explain why certain zircons give three different spectra. Some jargons (usually those of a green tint) contain a little uranium so combined that the characteristic spectrum is only faintly visible, whereas, after ignition, the intensity of the absorption bands is permanently increased often to a very great extent, and this more powerful action on light is accompanied by an increase in hardness and in specific gravity, sometimes as much as from $4^{\circ} 20$ to $4^{\circ} 60$. These changes are approximately proportional to the amount of uranic oxide in the various specimens, as shown by comparing the spectra of the blowpipe-beads. On the whole, since this abnormal type of spectrum is so characteristic of combination with zirconia, it appears probable that the effect of a high temperature is to cause the uranic oxide to combine more specially with the zirconia, as though the greater part existed naturally as a silicate, but after ignition as a zirconiate. We may also apply the same explanation in the case of zircons, more or less strongly coloured by other oxides, which become almost colourless when heated; and this unexplained peculiarity of zircons may depend on the fact of zirconia being able to play the part of both a base and an acid, which as compared with silica has an affinity for bases varying according to the temperature. The brown-red zircon from Ceylon, named at page 514 of my former paper, gives a spectrum precisely like that of the borax blowpipe-beads crystallised after treatment in the deoxidising flame. No doubt it contains uranous oxide. These facts thus clearly show that the various spectra which seemed to indicate the presence of a new element existing in three different physical conditions, are in reality only characteristic of the two oxides of uranium combined with zirconia, or not in combination. Perhaps some may think that my having been thus led astray shows that little or no reliance can be placed on the method of investigation employed, but I contend that the mistake was due to its being such an unexpectedly delicate test for uranium; moreover, the error was ultimately corrected by a further development of the same method. As far as the interests of science are concerned, there is no need to regret the general result. We have lost what appeared to be good evidence of a new earth, but have gained an almost entirely new system of blowpipe testing, which enables us to detect such a minute quantity of some substances as could not be recognised by the ordinary means.

H. C. SORBY

\section{THE RELATION OF THE STATE TO} SCIENCE

$W^{E}$ have referred in another column to Lieut.-Colonel Strange's valuable paper, read before the Society of Arts. The following is a report of the more important part of it. After giving a sketch of the history of the movement in favour of a recognition by the Government, of the necessity of defining the relations which should subsist between the State and scientific education throughout the country, commencing with the meeting of the British Association at Norwich in 1868, Colonel Strange proceeds to state the points which he thinks should be especially kept in view in the proposed inquiry. These are :-

x. The scope which the inquiry should inclure.

2. Some of the probable results of the inquiry.

3. The constitution of the Commission itself.

r. The Scope of the Inquiry. - The first thing to do will certainly be to take stock of what is now done by the State for advancing science. A reference to the parliamentary votes shows a considerable expenditure on science, in some form or other. The British Museum receives upwards of I00,000 a year, the South Kensington Museum 92,000l., and the Science and Art Schools 74,000l., but in these cases a large proportion goes to art, not wholly to science. * The Royal Observatories of Greenwich, Edinburgh, and the Cape of Good Hope, the Royal School of Mines, the Ordnance Survey, the Hydrographic Department of the Admiralty, are all scientific branches of the admi-

* The total amount voted in the Estimates, for $1869-70$, to maintain the "Science and Art Department of the United Kingdom" was 225,253 l. 